\title{
Insights of Intelligence Insiders on (Non-) Sharing Intelligence Behaviors
}

\author{
Musa Tüzüner \\ Center for Foreign Policy and Peace Research
}

\begin{abstract}
This study surveys the Turkish intelligence community's (non-) sharing intelligence behavior. The factors affecting failures to share intelligence and how to increase intelligence sharing practices are examined based on the views of Turkish intelligence insiders. These insiders'views reveal that the complexity of bureaucratic structures, lack of trust, compartmentalization, power, egoism, fear, informal groupings, lack of reciprocity and lack of feedback are the causes for non-sharing of intelligence. Policy solutions for shifting from non-sharing towards intelligence sharing behaviors is discussed in a new framework including respective government willingness, enhancing capacity of intelligence collection, building intelligence aquariums, creating rules for establishing new intelligence sharing, opening up new communication channels, training, and support for sharing culture. This framework argues that policy change should start first at the agency level, then at the community level and finally at the international level.
\end{abstract}

Keywords: Turkish intelligence community, intelligence sharing, intelligence reform

\section{Introduction}

While becoming an insider scholar ${ }^{1}$ in the field of Intelligence Studies, I have had the opportunity to meet with many practitioners and leading scholars studying intelligence ${ }^{2}$. During these interactions, we have often discussed how intelligence sharing is (not) working in different countries. It was from these discussions that I first got the idea to write a paper presenting insiders' perspectives on Turkish intelligence sharing behaviors. From that moment on, I began taking notes from my interactions with current and former Turkish intelligence officials about the intelligence sharing behavior of Turkish intelligence community members both within and among the main intelligence agencies of Turkey-the Turkish National edu.

Musa Tüzüner, Associate Professor, Senior Researcher, Center for Foreign Policy and Peace Research. Email: mtuzuner@kent.

1 Michael Warner, "Sources and methods for the study of intelligence," in Handbook of Intelligence Studies, ed. by Loch K. Johnson. (Routledge: New York, 2007), 17-27.

2 Many of these interactions occurred in a series of pioneering scientific intelligence meetings organized in Turkey to bring together both intelligence practitioners and scholars from foreign countries, including the NATO Advanced Research Workshop, Ankara, Turkey, December 6-8, 2007, organized by Musa Tuzuner and Ersel Aydınlı; the TNPA Intelligence Studies Research Center International Intelligence Symposium, Istanbul, Turkey, September 24-26, 2010, organized by Musa Tuzuner and Ersel Aydinli; the TAIEX Workshop, Ankara, Turkey, November 16-17, 2011, organized by Musa Tuzuner and Halil Baltacı; the Turkish Intelligence Agency International Conference, Ankara, Turkey, June 4-5, 2012, organized by Hakan Fidan. 
Intelligence Agency (MIT), the Turkish National Police Intelligence Agency, and the Military Intelligence Agencies.

Although intelligence officials are hesitant to give details and specific examples on (non-) sharing intelligence behaviors, I have been able to gather enough insights from my interactions to now present a preliminary look at insiders' views ${ }^{3}$ on how intelligence sharing should, and could, work. First, I will lay out the causes for non-sharing of intelligence and then present recommendations for increasing the level of intelligence sharing within the Turkish intelligence community.

\title{
2. The Need for Intelligence Sharing
}

There is a common belief in scientific inquiry that it is impossible to capture the whole reality about any particular phenomenon at any one time and place ${ }^{4}$. Each scientific paradigm looks at the same phenomena differently, and thus the scientific community needs rival schools of thoughts ${ }^{5}$. According to the pluralistic view of Paul Feyerabend, multiple research methods and paradigms are fundamental to going beyond partial truths to the whole truth ${ }^{6}$. Moreover, since no single scientific discipline can ever capture the full, big picture of any phenomenon, multiple disciplines should share their knowledge, scientific tools and methodologies ${ }^{7}$. In the social sciences, borrowing from different scientific disciplines can help scholars understand and solve societal problems, increase the quality of democracy, and enhance "human dignity" by providing the intelligence to aid policy decision makers ${ }^{8}$.

Similar to scientific disciplines, intelligence agencies also use their own tools and methodologies to make inquiries in order to understand societal threats, and submit the resulting intelligence products along with alternative policy options for politicians and policy makers to consider. Often, policy options against various threats may fail because they include only partial truths about the ensuing dangers. It can be assumed that the more intelligence is produced but not shared, the more likely it is for intelligence failures to occur. As one former head of an intelligence agency states:

\begin{abstract}
We were collecting daily intelligence in high volumes about a significant terrorist attack on our premises in the Eastern part of Turkey. As usual we were confident about the collected intelligence and did not get in touch with the other community members to make a plan in order to prevent the oncoming attack. Normally, based on the confirmed intelligence and its analysis, we were sure to successfully eliminate this attack without any losses. The terrorist attack started as we had expected, however, we were not able to stop them and had many losses. The reason for this failure was that the terrorist group had used a different strategy and tactic in its attack than we had expected. After this attack, we learned that the leader of that terrorist group was someone with whom I was very familiar and whose tactics and methods I knew well. Based on our intelligence, he was supposed to be in a terrorist camp in another country. If I had known that he was actually back in that region where the terrorist attack occurred, our strategy to prevent this terrorist group would have been very different. At that time, I wished that the other agencies in the intelligence community had shared with us their intelligence about that terrorist leader and his location.
\end{abstract}

\footnotetext{
3 Musa Tuzuner and Halil Baltacı are working to expand this preliminary view on Turkish intelligence sharing behavior in a comprehensive survey study.

Mark I. Lichbach, Is Rational Choice Theory All of Social Science? (Ann Arbor: The University of Michigan Press, 2003). Ibid.

Paul Feyerabend, Against Methods (London: New Left Books, 1975).

Lichbach, Is Rational Choice Theory All of Social Science?

Harold D. Lasswell, "The Policy Orientation," in The Policy Sciences: Recent Developments in Scope and Methods, ed. Daniel Lerner and Harold D. Lasswell. (Stanford University Press: Stanford, 1951), 3-15.
} 
This example clearly shows the need for sharing among intelligence agencies, but of course there can be barriers to such cooperation. For example, in the1990s, in order to eliminate the same kind of intelligence failure as was seen in the above case, I built up an intelligence aquarium, in which I included the bibliographic intelligence data of all terrorist group members within my jurisdiction. I periodically up-dated the intelligence aquarium not only with verified intelligence but also with raw and unverified intelligence, and shared these data with the unit members in my region as well as with other intelligence agencies' units in the intelligence community. As a result, intelligence community members working together against terrorist threats were able to carry out many successful operations. Ironically, after I had left that jurisdiction for a new post, my former subordinates accused me of having sold the bibliographic intelligence dataset to other intelligence agencies in the Turkish intelligence community and then proceeded to erase the database. For me, such accusations were the price of sharing intelligence. Fears of such outcomes along with a variety of other factors all may play a role in deterring intelligence officials from sharing intelligence.

\section{Non-Sharing Intelligence Behavior In The World}

My interactions with intelligence scholars and former intelligence officers first confirmed a general agreement that no intelligence agency is fully aware of the intelligence that other agencies have, and that each agency has vast amounts of unused intelligence waiting around to be connected to other bits of intelligence in other agencies. Since this sharing does not occur, the consensus was that intelligence failures seem inevitable. What are the causes for this failure to share intelligence? Based on my discussions, 22 factors can be considered as key in explaining hesitant attitudes towards sharing intelligence (see Table 1).

Obviously, the availability of intelligence in the hands of an agency is a must for intelligence sharing. However, even if intelligence is available within an agency, the agency might not want to share it. One reason for this is that intelligence is a very costly item. In the process of producing intelligence, a significant amount of an agency's budget is used, and equally often, a large amount of funding goes to developing intelligence which is of minimal or no use at all. Aside from the financial costs there may be other costs as well, since dangerous and difficult methods might have been used during the data collection process. With respect to international sharing, Intelligence officials also argue that once intelligence is produced, it takes on a kind of national identity, and because of this, some agencies and their members may not wish to share it. In short, all these factors make intelligence sharing less likely.

It is also necessary to consider that intelligence is produced by agencies based on an agency's own goals, interests, threats, and the ways in which that agency and its personnel understand these threats. If there is no commonality among the agencies, it is pointless to expect them to share intelligence. In other words, differences in intelligence agencies' goals, interests, threats and understandings of threats make sharing intelligence less likely.

It may also happen that heads of agencies may simply not want to share intelligence. One of the reasons for this is that intelligence is seen as a source of power for maximizing self-interests. Another is that intelligence is used as a tool for gaining benefits and credits. It is believed that when intelligence is shared, the power and credits may be passed to competing counterparts. It is not unusual then that rational intelligence actors may not be in favor of sharing intelligence that may result in losing the powers and credits attached to 
that intelligence. If the sharing of intelligence is to be done with an agency seen as a rival intelligence actor, the probability of non-sharing intelligence behaviors will increase.

\begin{tabular}{|c|c|}
\hline Lack of information in hand & Absence of intelligence in agencies \\
\hline Lack of reciprocity & Absence of true exchange of intelligence \\
\hline Cost & Intelligence is an expensive product \\
\hline Risk & Dangerous methods may be used in its production \\
\hline Difficulty & Difficult and secret methods may be used in its production \\
\hline Nationality & Intelligence is a national product \\
\hline Lack of common goal & The condition of having different goals in the intelligence community \\
\hline Lack of common interest & Each agency or officer has different interests \\
\hline Lack of common threat & Absence of common threat \\
\hline Lack of common understanding & Absence of common understanding among agencies about the nature of the threats \\
\hline Lack of permission & Head of an agency is not in favor of intelligence sharing \\
\hline Power & Intelligence is seen as a source of power (a zero-sum-game process) \\
\hline Credit-taking & General tendency of getting rewards for intelligence \\
\hline Competition & Entering into rivalries with each other for getting the same intelligence \\
\hline Lack of standardization & Absence of rules, norms and standards for gathering intelligence \\
\hline Lack of Trust & Absence of mutual trust in each other and in the quality of the other's intelligence \\
\hline Egoism & Common belief that one's own intelligence agency is the best \\
\hline $\begin{array}{l}\text { Concern over the security of } \\
\text { intelligence sources }\end{array}$ & Fear of exposing sources of intelligence \\
\hline Leaks & Fear of unwanted parties gaining access to shared intelligence \\
\hline Lack of feedback & Absence of feedback on earlier shared intelligence \\
\hline
\end{tabular}

Another must for intelligence sharing is having standards for how to do it. Some intelligence officers justify their unwillingness to share intelligence as stemming from the lack of standards for determining how this sharing should be accomplished. Nevertheless, even when there are rules, intelligence actors may still not want to share intelligence. One 
reason may be an absence of trust. Intelligence actors are more likely not to share intelligence with an agency they consider as untrustworthy. Reluctance to share can also stem from egoism. If one agency acts as if it is the best among the various agencies, this behavior will surely irritate the others and may lead them to give up on sharing intelligence. Yet another reason that is often given is fear of exposing intelligence sources and of a possible leaking of intelligence to unwanted parties. Once intelligence is shared, there is little control over how it may be handled or used by the other agency, so feelings of unease and doubt are common. Yet another reason cited is the lack of feedback mechanisms. After an agency has shared intelligence, there is the general expectation that they will receive some kind of feedback about it. If an agency or intelligence actor has had experiences of not receiving such feedback in past cases, they will likely limit their sharing behaviors, at least to those agencies that they feel are more likely to provide feedback. Overall these factors, each of which is discussed in detail below, can be highlighted as negatively affecting intelligence sharing behaviors.

\section{Intelligence Non-Sharing Behaviors in Turkey}

Turkish intelligence practitioners with whom I've spoken over the years have pointed out certain specific factors behind their negative attitudes towards intelligence sharing-though they were not always comfortable with sharing details or providing specific examples. They did, however, reveal to me some overall factors that are frequently discussed not just among Turkish intelligence community members but also between the Turkish intelligence community and foreign intelligence agencies.

The complexity of bureaucratic structures is an often noted cause for limited intelligence sharing within an agency. Each individual intelligence agency has its own huge bureaucratic structure and yet there are no single units to coordinate intelligence sharing within an agency. Based on the principle of division of labor, each intelligence unit in an agency has different tasks. Each unit is supposed to concentrate on its job and not to interfere with the work of the other units. Because of this division of labor, each unit naturally has limited knowledge about each other's tasks and is therefore not able even to know what might possibly be shared with the other units. Without regulations on how to share intelligence among an agency's units and lacking any within-unit intelligence aquariums that could be connected to a larger scale agency-wide intelligence aquarium, responsibility for the sharing of intelligence is left on the shoulders of the individual units. In such an environment, unit chiefs generally devise informal - and often deterring - rules for sharing intelligence. For example, one former intelligence officer told me the following:

\footnotetext{
I was visiting an intelligence unit in the region. While walking in the hall I saw a big sign saying "DO NOT SHARE INTELLIGENCE WITHOUT ASKING THE BOSS". When I asked my counterpart in that agency what the boss's rules were for intelligence sharing, he told me simply that there were no rules.
}

Other former intelligence officers have noted that sometimes there are nonsensical rules within the agency that serve to prevent any kind of intelligence sharing. Though they were reluctant to give examples about such rules, there have been claims of such practices as unit chiefs setting rules based on their own self-interests, personal characteristics, egoism, and so on. 
In Turkey there are clear overlaps in the organizational missions of the three intelligence agencies, ${ }^{9}$ and there are no clear boundaries delineating their responsibilities. With such structural characteristics, each agency is in a sense sharing the necessary resources to deal with the same threats, and the availability or lack of resources puts these organizations in a self-help position to prevent the threats. While all three agencies may at any given point be dealing with targeting the very same threats, they are in a competition to find human intelligence sources from the same target pool. As a result, it is not uncommon to have the same informant working for at least two of the agencies. All of this serves to actually reduce the likelihood for intelligence sharing within the intelligence community. Moreover, the lack of a clear division of labor in the Turkish intelligence community naturally results in not having any formal communication channels, regulations, or rules about what to share, how much to share, how to share and when to share. The unregulated realm of sharing intelligence is thus left to the discretion of the head of each agency. Most often, these agency heads prefer a centralized system for sharing intelligence among the agencies. According to such a system, each time intelligence sharing is about to occur, the approval of the head of the agency is required. In the end, such a system based on the discretion of the agency head is more likely to reduce the sharing of intelligence among intelligence agencies.

Lack of trust is arguably the single most important factor for reducing intelligence sharing within or among agencies. Mutual trust in one's counterparts and in the actual intelligence is a must for productive intelligence sharing, and any suspicions about individuals or the collected intelligence in an agency, will immediately put a halt to intelligence sharing. As one former intelligence officer told me:

\footnotetext{
I was working as an intelligence collector. One day, my boss told me that he had lost his trust in one of my intelligence sources because of the incomplete intelligence he was providing. I felt really bad because I had tried hard to convince my boss to let him work with us. So I stopped sharing the intelligence I got from that source with my boss. Some time later, a horrible terrorist attack occurred. I got some intelligence from that same informer about some suspects in the attacks. I didn't share this intelligence with my boss, instead, I passed it through informal channels to the operation units, and they captured the suspects.
}

There are many other examples similar to the above, clearly showing that lack of trust is a primary factor for hindering intelligence sharing in an agency. In yet another example, a former senior intelligence officer reported the following to me:

One day, my informer told me that a terrorist wanted him to go a rural area where a military
operation was going on in order to bring him a large sum of money (two million Deutsche
Mark and one million US Dollars). I did not share this intelligence with my chief of
intelligence unit because, for reasons I can't speak about, I had lost my trust in him.

The lack of trust within and among the Turkish intelligence agencies seems to be so prevalent that it causes a significant reduction in intelligence sharing. For whatever reasons, intelligence officers claim that each agency sees the others as its rival. They also note that each intelligence agency has its own distinct institutional identity. In the constructing of these institutional identities, one feature has been the defining of the other agencies as competitors

9 Because of overlap in the agencies' missions, conflicts may occur while they are pursuing their tasks. Recent examples of this can be seen in the Hakan Fidan case in 2012 and the Truck case in 2014. For more information on the Hakan Fidan case in 2012, see: Ivan Watson and Yesim Comert, “Arrest warrant issued for former Turkish intelligence chief," CNN, February 10, 2012, accessed June 1, 2014, http://edition.cnn.com/2012/02/10/world/turkey-intel-agents/. For more information on the Truck case in 2014, see: "Turkish soldier arrested in probe into search of intelligence vehicles," BBC Monitoring: International Reports, April 11, 2014, accessed June 1, 2014, http://www.lexisnexis.com/lnacui2api/returnTo.do?returnToKey=20_T20164650687. 
rather than partners. I have observed examples of this firsthand while teaching groups of intelligence community members. Even in the classroom or in interactions before and after class, unless absolutely necessary, different agency members are hesitant to communicate with each other.

Some intelligence officers claim that this lack of trust comes from the potential of loyalties to alternate informal groupings different from those in their own agencies. In addition to the lack of trust in individuals or institutions, there may also be a lack of trust in the actual intelligence collected by other agencies. Whatever the cause, if either part lacks trust in the other, it greatly reduces the likelihood of intelligence sharing among the domestic intelligence agencies.

Lack of trust is also the leading reason negatively impacting Turkish intelligence community members' intelligence sharing with foreign intelligence agencies. It is claimed that the lack of trust stems from the conflict-ridden historical interactions with foreign countries, and the resulting reluctance to share intelligence with historical enemies. In addition to historical experiences however, current practices also reduce the level of trust in foreign intelligence agencies. For example, one intelligence officer stated that:

\begin{abstract}
A team of intelligence officers went to a neighboring country with a folder of documents about one of the terrorist group activities in both our countries. We shared the intelligence about the threats and it seemed as if we had established a good cooperation against the threat. A couple of months later, we got intelligence from our sources that our neighbor intelligence agency had shared our intelligence with the terrorist groups. After receiving this intelligence, we stopped cooperating with them. They are still asking to enhance cooperation to include the other threats, but we keep our silence, pretending that we are still willing to do so.
\end{abstract}

As seen from this example, once trust is lost there is little hope for productive intelligence sharing.

Compartmentalization is also seen as an important factor preventing intelligence sharing within an agency. Ordinarily the logic is that each unit should collect intelligence directed to its own mission, but should share relevant intelligence with other units. In reality, this is sometimes understood as each unit should know only the intelligence relevant to its mission and should avoid revealing that intelligence to the other units of the agency. In the words of a former senior intelligence officer:

When I first entered the intelligence world, there was a word view of "don't ask anything and just do whatever you're asked." Also, my boss told me not to share anything with anybody. I thought this compartmentalization was necessary for the sake of the intelligence job. After some time passed, one of my colleagues from another unit asked me to give him the newspaper. He added that there was news about their target in that newspaper. I said that I was not supposed to share that newspaper with him. I behaved like that because I was indoctrinated about compartmentalization in that way.

Another former intelligence officer reported the following:

When I was working at the intelligence agency, there was one thing that was really bothering me. Whenever I visited another bureau and had a cup of tea with my colleague, I realized that he would place all the documents on his desk upside-down. I hate this behavior within our agencies but I cannot do anything about it.

This type of understanding has gone even further with technological developments. In recent decades, there is a general tendency to install electronic systems that allow only members 
of a particular unit to obtain access. This practice gives the image of "just do your business (collect your intelligence by yourself) and you do not need any help (intelligence) from other units". Again, compartmentalization is seen as the source of the attitude behind the failure to share intelligence among or even within agencies. There is a further effect as well however, as isolating units from each other reduces the interaction among unit members and their familiarity with each other's jobs. As a result, even if willing to share, intelligence officers end up in a position of not knowing what to share or with whom.

Power comes from the intelligence one has in hand. In other words, collected intelligence is power for an intelligence officer, who, in turn, may not want to lose that power by sharing it. Since power allows them to realize their self-interests, such as getting promotions, receiving money rewards, and being recognized in the agency as successful, some individuals may consider that any shared intelligence will increase their rivals' power. As one former intelligence chief reported:

\footnotetext{
Our boss set up an intelligence flowing system that made it so that the incoming intelligence only flowed to him. He tried to keep all his subordinates separate from each other and never gave them a chance to come together and collaborate. Nobody knew what was going on in the unit except for him. The boss never wanted intelligence collectors to write reports on the collected intelligence, instead, he preferred to meet separately with the intelligence collectors and get the intelligence from them verbally. We were unhappy with the implications of this system because we really didn't know what to do about the threats we were dealing with. He always told us what to look out for while we were out for intelligence collection. After some time passed, he became popular in the agency and was credited with all the achievements. We later realized that if the boss saw someone as a rival for his position, he would find a way to send him or her out of the unit. After he retired, a new boss came. The new boss had a meeting with us and asked how many human intelligence resources we had. We said we didn't know anything about the informers. Our former boss had kept all the intelligence and when needed, acted as if he had just collected it by himself. Our new boss told us that the former boss had only told him about two or three human intelligence sources but we were aware of the fact that there were more than ten.
}

This case clearly shows an example of highly self-interested and power-seeking behavior, and how such behaviors are likely to reduce intelligence sharing practices within an agency.

Some reasons for such power-seeking and self-interested behaviors when it comes to agency heads may be to maximize the overall agency's budget, to get closer to political figures, to increase the agency's impact on national policy decision-making, or to increase the number of successfully conducted operations that their own agency makes over those of other agencies. It is claimed that when intelligence is shared, power could shift to a rival intelligence agency allowing that agency to become the 'leader' of the ongoing competition among them. In short, in the intelligence community, even at the institutional level, self-interests too often take precedence over national or common interests, thus reducing intelligence sharing among the various agencies.

Egoism is also commonly noted as negatively affecting intelligence sharing within Turkish intelligence agencies. It can be assumed that the more we see signs of egoism among supervisors, the less likely we are to see intelligence sharing. Sometimes these egoistic individuals are called as 'gods' in the agency, based on their attitudes of seeming to know everything best. They have extreme, perhaps over-stated, self-confidence in the reliability of their intelligence and their own ability to make well-analyzed intelligence products. 
Insights of Intelligence...

According to them, their intuition can effectively fill the intelligence gap. Because of this egoistic behavior, their subordinates may be reluctant or even intimidated to share the intelligence they gather with them. For example, a former intelligence officer stated that:

\footnotetext{
Our chief of unit always acted as if he was an expert in intelligence work and that we had a long way to go before we could reach his expertise. Whatever we told him, he said he already knew. He always gave us directions on how to collect intelligence. We were therefore hesitant to share all the intelligence we obtained with him. One day I collected intelligence from a source about a couple of terrorists who had come from the rural area and were staying at my informer's neighbor's house downtown. I did not want to share this intelligence with my chief because I thought he must have already gotten this kind of intelligence from his own sources. After some time passed, I found out that my chief had not gotten this intelligence from his sources and then I realized that he might have been bluffing in the past.
}

As seen from the example, subordinates may believe that such egoists somehow will gather the same intelligence they have obtained, and therefore there is no need to share all the intelligence with them. In other words, if there is a sign of egoism in an agency, subordinates are less likely to share their intelligence. The signs of egoism can also be seen at the level of regional units in an intelligence agency. In this case, the units which consider themselves more capable are more likely to unilaterally take the necessary measures against threats and not see a need for sharing intelligence with other regional units.

Finally, egoism is also a common factor negatively affecting intelligence sharing behavior among entire intelligence agencies. Most Turkish intelligence community members will assert that theirs is the most professional intelligence agency and that, in essence, "we are the best and all intelligence should be shared with us". At the same time, most admit that the presence of this image in the intelligence community has a negative impact on intelligence sharing. For example, a senior intelligence officer said:

\footnotetext{
One of the intelligence agencies is trying to give the image as if it is the most important intelligence agency amongst all the others. One day, there was a high level formal meeting of intelligence community members. When I was sharing intelligence with the other agency officials, one of their units interrupted my presentation and stated that he was already aware of what I was informing them about. However, I am certain that his agency was not aware of anything I was talking about because the chair of the meeting told me that other agencies had not shared any information before the meeting. After that meeting, I only shared trivial pieces of intelligence with them.
}

As seen from the example, the sign of egoism does seem to affect sharing practices and ultimately to reduce the level of shared intelligence.

Fear is also an important factor reducing intelligence sharing within an agency. There is a common belief that the more intelligence that is shared, the more problems are likely to be encountered, thus making it seem preferable not to share at all. Intelligence officers generally have a fear of exposing the sources of intelligence, of violating the principle of secrecy of intelligence, and of experiencing problems after sharing the intelligence, particularly with respect to unconfirmed, 'raw' intelligence.

The main principle of intelligence work is the security of one's intelligence sources. While sharing intelligence therefore, the first priority is not to expose those sources. Even in cases of just minimal concern or unease, officers or units are still more likely not to share the intelligence with other officials or units of an agency. The fear of course is that if there is 
any chance of a source being exposed, the possible result is not being able to gain any further intelligence from that source. Additionally, officers are highly reluctant to lose credibility in the eyes of their sources. Some intelligence officers also reported having witnessed human sources spreading rumors about intelligence agencies putting their sources' lives in danger and therefore not being trustable. Such unwanted results might scare intelligence agency officers and may lead them not to share intelligence.

Fear of violating the secrecy of intelligence is also a cause for reducing the rate of intelligence sharing. It seems to be the case that when intelligence is shared with other units of an agency, the receiving units are less conscientious about the secrecy of that intelligence. Officers say that the more that intelligence is shared, the more it loses its secrecy. Some officers reported, for example, having witnessed many times that their bosses were talking about shared intelligence with other individuals who were not supposed to be informed about such kind of intelligence. In short, an officer's or unit's fear of being accused of violating intelligence secrecy principles may lead to an attitude of not sharing intelligence.

In some cases, the results of shared raw intelligence worries intelligence officers and pressures them not to share such intelligence until it is verified and completed. There have been various cases in Turkey that justify this concern. For example, in the case of Hrant Dink, a Turkish-Armenian journalist who was assassinated in 2007, unverified intelligence had been shared among the police intelligence agencies. After his death, all recipients of the shared intelligence were accused of not having done their job and were prosecuted. On the other hand, failure to share raw intelligence can also cause problems. In one example, intelligence officers received intelligence from a villager that terrorists were planning an attack. Because the villager had heard this from a terrorist passing by their village that day, there was no opportunity to get further detailed intelligence. In this case the officer opted not to share this unconfirmed intelligence with his units and one day later a terrorist attack occurred. This and numerous similar cases show that some officers and units tend to only share intelligence when it is fully verified, and to be hesitant to share raw intelligence.

Informal Groupings may also be a cause of reduced intelligence sharing. Such groups are likely to be seen in intelligence agencies, based on principles like different ideologies, religious sects, ethnic roots and so on. Occasionally, some of these groups may become more influential in an agency over different time periods. It is not uncommon for these informal groups to have claims that "we love our homeland better than other groups and; so, it is our duty to save the homeland from the threats". Based on this philosophical foundation the group members see themselves above the bureaucratic structure, and seek to hold allimportant and strategic intelligence in their own hands and use that intelligence to affect the strategic moves against the threats. As a general rule, members of these informal groupings do not want to share intelligence with non-members, fearing they will not use it effectively or that it will be wasted in the other group. In short, it is less likely to see different informal group members sharing intelligence with one another.

With respect to inter-agency sharing, since different informal groups might dominate within different intelligence agencies at any given time, intelligence sharing among the agencies is less likely as well. In recent decades, different informal groups have been emerging and increasing their influence in intelligence agencies. As a result, a decrease in sharing behaviors has come to be seen as the norm by these agencies. 
Lack of reciprocity is a key factor blamed for reducing intelligence sharing between Turkish intelligence community members and foreign intelligence agencies. Sharing intelligence is of course not a one-way action, and includes the expectation of exchange. For this to occur, both sides should have some intelligence or at least a valid promise of some, in order to start sharing intelligence behaviors. This is not always the case, however, as reported by some former intelligence officers:

\footnotetext{
Most of our strategic partners generally ask us about some information concerning terrorist targets without showing us any willingness to exchange it with other intelligence that we wanted in the past. If we are not going to get anything out of this bargain, then why bargain in the first place? As a result of this, we refuse their demands.
}

In short, one-way intelligence sharing is bound to not last long.

Less common but also sometimes noted, lack of feedback may be a factor negatively impacting intelligence sharing among the intelligence agencies. Intelligence agencies have some expectation of getting feedback from agencies with whom they have shared intelligence. They would like to see how the shared intelligence has been used and how the shared intelligence contributed to the analytical or operational work of that agency. The absence of this feedback discourages an intelligence agency from further intelligence sharing.

Finally, intelligence officers have highlighted a variety of other common reasons that could explain why intelligence sharing is less likely to occur both within the Turkish intelligence community and between it and foreign intelligence agencies. These are respectively the lack of common goals, lack of common threats, and simple lack of interest. All these factors could be considered natural outcomes of a realist reality in which self-interested and self-help states are seeking self-security in an anarchic system.

\section{Towards Turkish Intelligence Sharing Behavior}

At a recent workshop, former senior intelligence officials and intelligence scholars from different parts of the world met to discuss what should be done to increase intelligence sharing at both the national and international levels ${ }^{10}$. They laid out some recommendations for increasing intelligence sharing based on their long experiences in the intelligence field. From those discussions, I have formed a framework explaining what should be done for increasing intelligence-sharing behavior (see Table-2). The common starting idea that emerged from these intelligence officials' views, was that essential measures should first be taken at the national level and then at the international level.

According to this framework, in order to increase sharing intelligence at the national and international levels, the willingness of high governmental figures is seen as necessary. Without their support, it seems very difficult to bring about changes in intelligence sharing behavior. Moreover, if an agency has nothing in its hands, then sharing seems impossible. So, each agency should clearly define its own intelligence needs and then determine which parts of this intelligence can be collected independently and which parts can be gathered through sharing with other agencies. In order to collect intelligence independently, an agency's capacity for collecting should be upgraded and all sorts of intelligence should be kept flowing into the agency. Once the different types of necessary intelligence are gathered, they should be accumulated in an intelligence aquarium. The next step is to set

\footnotetext{
10 Tuzuner, ed. Intelligence Cooperation Practices.
} 
up rules for intelligence sharing practices. Sharing rules and standards - both national and international - must be defined by formal regulations and agreements. Based on these rules, new communication channels among the agencies can be created. These channels might be in the form of liaison officers, regional groupings, formal meetings and feedback mechanisms. Once an intelligence sharing system has been set up, trainings should be started to change old mindsets of intelligence sharing into new ones that believe to be more in the usefulness of sharing for each counterpart. The final step is to create a supportive environment for the new culture of intelligence sharing.

Table 2- Factors for Global Intelligence Sharing

\begin{tabular}{|c|c|}
\hline Government willingness & Governments should be ready to share \\
\hline $\begin{array}{l}\text { Enhancing Capacity in } \\
\text { Intelligence Collection }\end{array}$ & Agencies' current capacity building for collecting intelligence should be enhanced \\
\hline $\begin{array}{l}\text { Building an } \\
\text { Intelligence Aquarium }\end{array}$ & Agencies need intelligence aquariums for the collected intelligence \\
\hline $\begin{array}{l}\text { Setting up rules for new } \\
\text { intelligence sharing }\end{array}$ & $\begin{array}{l}\text { Rules and standards for opening up new intelligence sharing via formal regulations } \\
\text { and agreements should be defined }\end{array}$ \\
\hline $\begin{array}{l}\text { Opening up } \\
\text { New Communication Channels }\end{array}$ & $\begin{array}{l}\text { New communication channels among intelligence agencies should be created, } \\
\text { including: } \\
\text {-Liaison officers (Individual relationships) } \\
\text {-Establishing regional groupings for intelligence sharing } \\
\text {-Formal arrangement of meetings among agencies } \\
\text {-Setting up feedback mechanisms for shared intelligence }\end{array}$ \\
\hline Training & Out-dated mindsets towards sharing intelligence should be changed into new ones \\
\hline $\begin{array}{l}\text { Support for } \\
\text { Sharing Culture }\end{array}$ & A culture of sharing should be encouraged \\
\hline
\end{tabular}

Similar to their international counterparts, the Turkish former intelligence officers explicitly recommended that in order to increase intelligence sharing, the necessary measures should first be taken within domestic agencies, then in the Turkish (or other national) intelligence communities overall, and finally at the international level.

Governmental Willingness: The common view of the intelligence officials shows us that Turkish high-level governmental officials' willingness is definitely required for any kind of change at both the national and international levels of intelligence sharing. Without such commitment, all initiated actions will quickly fade. For example, in 2010 I set up an Intelligence Studies Master (MA) Program that would help develop students from the intelligence, security, and civilian sectors. One of our goals is to contribute indirectly to increasing intelligence coordination and cooperation within the Turkish intelligence community. Heads of intelligence agencies have shown us their willingness and desire to have their intelligence officials apply to the program. One of my students told me:

Since our boss showed his consent for us joining the master program, it was easy to apply to the program and to ignore the pressures from mid-level supervisors, who would rather have us not attend these courses. 
As seen from this example, if the heads of the intelligence agencies did not show their eagerness in favor of their employees attending the intelligence master program, we would not have been able to realize our goal of indirectly increasing coordination among Turkish intelligence members in the future.

Enhancing the Capacity of Intelligence Collection: Turkish Intelligence officials seem satisfied with the current capacity of their agencies for collecting intelligence. However, some policy changes appear necessary to enhance the overall capacity of these agencies. The first recommended policy change is to select and promote those people who have the skills and abilities to do the job effectively. The second needed policy change is to give up strict compartmentalization. This problem could be addressed by creating some common working areas where officers who are doing similar jobs could work alongside each other. Also, teamwork should be encouraged as the common working style throughout the agencies. The third policy change is about informal groupings. It is stated that in the process of intelligence production, the dominance of one informal group over others should not be allowed. Each informal group's members should be included in the production of intelligence. It is believed that such new policy options would change the overall quality of the intelligence, and would allow the holders of intelligence to share it without doubts, so that this intelligence, as a form of power, would work to the benefit of more common and national interests.

To increase the overall capacity of the Turkish intelligence community, it is also recommended that a joint task force for each threat be established, and that joint projects be conducted. For example, Turkish intelligence agencies generally deal with the same threats. In some cases, a joint working group can be formed and can start collecting intelligence. Such a practice would increase mutual trust within the intelligence community, save the resources of each intelligence agency, and help to eliminate the mindset of seeing each other as rivals. The idea of joint intelligence task forces at the international level could also increase mutual trust and common understandings of threats.

Building Intelligence Aquariums: The expert intelligence officers also found common agreement on the idea of having an intelligence aquarium for each agency and for the community. These aquariums should include all types of intelligence collected. Even if the intelligence is small, incomplete and unverified, it should still be in the aquarium. Such intelligence aquariums would make it easier and faster for agencies to reach the intelligence. In these aquariums, pieces of intelligence would find their way to couple up and fill in intelligence gaps. If these aquariums were accompanied by a new set of intelligence sharing rules, intelligence gaps would grow ever smaller.

Setting up rules for new intelligence sharing: Once we have intelligence in an aquarium, it is ready to be shared. Sharing within agencies, among agencies in a community and with foreign agencies should be done according to the laws, regulations, and rules. These rules should clearly define what to share, whom to share with, how to share, when to share, how much to share, and what not to share. They should also regulate not only centralized intelligence sharing but also field level intelligence sharing, the security of the human intelligence sources, the standards of sharing intelligence among units and agencies, and secrecy of shared intelligence. This policy option is believed to be able to reduce the concerns of the intelligence officers on the secrecy of intelligence and take the burden off intelligence units and agency chiefs by generating rules for intelligence sharing. 
Opening up New Communication Channels: After setting up the rules, new communication and coordinating channels are necessary at the national and international levels. Within the intelligence community, the advised channels include periodical official meetings among the heads of each intelligence agency, representatives of each intelligence agency and representatives of agency units that are dealing with common threats. These meetings would help to familiarize all sides both personally and professionally, and to increase their previously limited knowledge of each other's jobs. At the international level, the possible communication channel could be in the form of liaison officers. Whatever the nature of the communication channel, they should have the characteristics of mutual intelligence sharing and of serving as a feedback mechanism.

Training: Once there are new rules and new sharing channels in place, the desired intelligence sharing behaviors can be given to intelligence officials via training. Naturally, the intelligence officials should master the new rules, procedures, standards, and communication channels and their function. With these trainings, efforts should be made to change current, resisting mindsets on intelligence sharing. Some of the suggested trainings within the agency should be specifically designed to make clear national interests and the common goals of the whole intelligence community; to show how shared intelligence might increase the success of individuals, units and the agency; to present how egoistic behavior might conflict with an agency's national interests and jeopardize the overall success; and to increase intelligence officers' skills, leading to a closing of the intelligence gap in the various units and agencies.

In addition to agency level trainings, it is advised to have community level joint trainings serving to personnel from the different intelligence agencies. The goals of these trainings should be to increase the intelligence community members' capability of conducting joint tasks such as intelligence collection and operation on common threats; to show how one agency's self-interests might result in disturbing other intelligence agencies' missions oriented to national interests; to build up mutual trust among intelligence community members; to change self-interested mindsets to national interested mindsets; and to conduct activities that can raise awareness of the importance of sharing intelligence in the intelligence community.

At the international level, joint trainings would be useful for changing the mindsets for joint intelligence task forces against common threats. They should be designed to increase the ability to conduct joint intelligence tasks, and as a result, these trainings should increase mutual trust among international intelligence partners.

Support for a Sharing Culture: One final recommendation is to organize some social activities within the agencies and in the intelligence community as a whole to increase the informal social ties among intelligence officials. This social capital building process will contribute to building a positive atmosphere that can keep a newly emerging intelligence sharing culture alive in the agencies and intelligence community.

\section{Conclusion}

In democratic countries, intelligence officials, like scientists, are working to enhance democratic life by producing intelligence for the policy makers who are responsible for making good policies for the society. In order to be most effective, intelligence agencies must share the intelligence they have collected. However, intelligence sharing behavior does 
not always operate as needed. Political scientist Terry Moe has argued that bureaucratic structures are intentionally created to fail ${ }^{11}$. We hope that this is not the case in Turkey.

To understand the specific factors behind non-sharing intelligence behaviors and how things could be improved towards sharing at both the national and the international levels, the data for this article were taken from interactions with Turkish intelligence officials and from informal discussions with international intelligence practitioners and scholars. These insiders' insights show us how key factors such as the complexity of bureaucratic structures, the lack of trust, compartmentalization, power, egotism, fear, informal groupings, lack of reciprocity and lack of feedback are the main causes of non-sharing intelligence behavior. According to the common view of intelligence insiders, policy chances on intelligence sharing behavior should start first at the agency level, then proceed to the community/national level and finally to the international level. These changes should include respectively government willingness, enhancing capacities for intelligence collection, building intelligence aquariums, setting up rules for new intelligence sharing, opening up new communication channels, training, and providing support for a sharing culture.

This study is intended to open up a discussion on how to reform intelligence sharing behavior in Turkey. It is hoped that future studies will ultimately contribute to even broader reform of the intelligence sector worldwide.

11 Terry Moe, "The Politics of Bureaucratic Structure," in Can the Government Govern, ed. John E. Chubb and Paul E. Peterson (Washington, DC: Brookings Institution Press, 1989). 


\section{Bibliography}

"Democratic Intelligence Governance." Paper presented at the TNPA Intelligence Studies Research Center International Intelligence Symposium, Istanbul, Turkey, September 24-26, 2010.

"Democratic Values and Intelligence Practices." Paper presented at the TAIEX Workshop, Ankara, Turkey, November 16-17, 2011.

“ICINTA'12 International Conference on Intelligence Analysis.” Paper presented at the Turkish Intelligence Agency International Conference, Ankara, Turkey, June 4-5, 2012.

"International and National Intelligence Cooperation Practices." Paper presented at the NATO Advanced Research Workshop, Ankara, Turkey, December 6-8, 2007.

Feyerabend, Paul. Against Methods. London: New Left Books, 1975.

Lasswell, Harold D. "The Policy Orientation.” In The Policy Sciences: Recent Developments in Scope and Methods, edited by Daniel Lerner and Harold D. Lasswell, 3-15. Stanford University Press: Stanford, 1951.

Lichbach, Mark I. Is Rational Choice Theory All of Social Science? Ann Arbor: The University of Michigan Press, 2003.

Moe, Terry. “The Politics of Bureaucratic Structure.” In Can the Government Govern, edited by John E. Chubb and Paul E. Peterson. Washington, DC: Brookings Institution Press, 1989.

"Turkish soldier arrested in probe into search of intelligence vehicles." BBC Monitoring: International Reports, April 11, 2014. Accessed June 1, 2014. http://www.lexisnexis .com/lnacui2api/returnTo.do?returnToKey=20_ T20164650687.

Tuzuner, Musa ed. Intelligence Cooperation Practices in the 21st. Century: Towards a Culture of Sharing. IOS Press: Amsterdam, Holland, 2010.

Warner, Michael. "Sources and methods for the study of intelligence." In Handbook of Intelligence Studies, edited by Loch K. Johnson, 17-27. Routledge: New York, 2007.

Watson, Ivan, and Yesim Comert. "Arrest warrant issued for former Turkish intelligence chief." CNN, February 10, 2012. Accessed June 1, 2014.http://edition.cnn.com/2012/02/10/ world/turkey-intel-agents/. 